\title{
Using Spectrum Auctions to Enhance Competition in Wireless Services
}

\author{
Peter Cramton University of Maryland \\ Evan Kwerel Federal Communications Commission \\ Gregory Rosston Stanford University \\ Andrzej Skrzypacz Stanford University
}

\begin{abstract}
Spectrum auctions are used by governments to assign and price licenses for wireless communications. Effective auction design recognizes the importance of competition, not only in the auction but also in the downstream market for wireless communications. This paper examines several instruments that regulators can use to enhance competition and thereby improve market outcomes.
\end{abstract}

\section{Introduction}

Since their introduction in 1994, spectrum auctions have been remarkably successful in assigning and pricing spectrum. The United States has conducted more than 70 auctions to assign thousands of wireless licenses. These licenses have been put to use by wireless operators to create a competitive and rapidly growing wireless industry. Assigning spectrum licenses to private for-profit companies throughout most of the world, including developed and developing countries, has led to rapid development of wireless telecommunications. Indeed, wireless communications have become a factor in economic development. Good spectrum policy and spectrum auctions will play an important role in continued success.

We believe that the primary goal of spectrum policy and spectrum auctions should be economic efficiency-that is, putting the spectrum to its best use. Unfortunately, an auction that awards the spectrum to bidders with the highest

The views expressed are those of the authors and are not those of the Federal Communications Commission. Cramton thanks the National Science Foundation for funding. The authors thank Patrick DeGraba and Martha Stancill for helpful comments. Cramton, Rosston, and Skrzypacz have provided advice to governments and bidders in auctions. 
values may not assure economic efficiency because the bidders' private values for the spectrum may differ from social values as a result of market structure issues (Borenstein 1988). For example, an incumbent will include in its private value not only its use value of the spectrum but also the value of keeping the spectrum from a competitor. Effective policy must recognize competition issues in the downstream market for wireless services.

Coase's (1959, p. 16) advocating of spectrum auctions recognized the importance of addressing competition: "the problem of monopoly is clearly one to be taken seriously." Nonetheless, he wisely focused on the affirmative case for auctions, leaving for later questions about competition as those are important regardless of the spectrum allocation methodology.

This paper examines instruments available to the regulator to address competition issues in both spectrum auctions and the resulting downstream markets for wireless services. These instruments include set-asides, bidding credits, spectrum caps, band plan, auction format, and antitrust enforcement/merger review policy. Each of these instruments, under the right circumstances, can play a role in enhancing competition.

There are, however, no easy answers. The instruments must be used with care to avoid unintended harm. The purpose of this paper is better to understand the properties of the various options. In the end, regulators must rely on judgment in establishing competition policy-a judgment informed by a thorough understanding of the particular setting, practical experience, and how the instruments work.

Perhaps the most important step the government can take to enhance competition is making more spectrum available and making the spectrum available sooner rather than later. Spectrum is an essential input in wireless communications. More spectrum supports more competition. Each spectrum auction is a new opportunity for a potential entrant or a new service and improved coverage. There is strong empirical support for the hypothesis that additional spectrum enhances competition, lowers consumer prices, and increases economic welfare (Hazlett and Munoz 2009).

Our analysis of policy options is not exhaustive. We focus on options that are most closely related to spectrum auctions. Other policies, such as mandatory tower sharing and mandatory roaming, may be desirable for reducing entry barriers and network costs, but we do not address them here.

We begin by discussing the goals of the regulator. Then we discuss the various options available to the regulator to promote competitive goals and give examples. We present models that motivate the need for various instruments and suggest where the instruments are apt to be most effective. Finally, we discuss the use of the methods in actual spectrum auctions. 


\section{Goals}

We consider the primary goal of the regulator to be economic efficiencythat is, putting the spectrum to its best use. Best use is defined as assignment of licenses that maximizes the consumer value of wireless services less the cost of producing those services. In the simplest settings (for example, with one license for sale and no incumbents, with bidders that can correctly assess profit opportunities, and with an assumption known as private values), if postauction profits are an increasing function of postauction social value created by the winner, then an ascending auction can achieve an efficient allocation of the license. If a firm expects the highest profit because it will offer a service of especially high consumer value at especially low cost, then awarding the spectrum to the firm with the highest value (and hence the highest willingness to pay) is aligned with maximizing efficiency.

Most spectrum auctions, however, are held in a much more complex environment. In particular, a common asymmetry in the auctions is the distinction between an incumbent and an entrant. The incumbent has existing customers, network infrastructure, and spectrum; the entrant does not. Moreover, the incumbent can potentially limit entry and hence competition by purchasing additional spectrum that would otherwise go to an entrant. The trade-off is not trivial. On one hand, the incumbent may have important economies of scale and scope that would allow it to use the additional spectrum more efficiently. On the other hand, part of the willingness to pay for the incumbent in the auction comes from the value of deterring new entry, which is bad for overall efficiency for the standard market power reasons and may be bad for the dynamic evolution of the service if the threat of competition is necessary to speed up the build out and development of new technologies.

Competition policy seeks to address this potential market failure by encouraging competition in the provision of wireless services. Since licenses are awarded via auctions, to create new entry in the provision of wireless services it is often necessary to first encourage entry into auctions; the expectation that incumbents are likely to have some synergy value for new spectrum and have additional incentives to bid aggressively in the auction to deter entry is often a strong deterrent for potential new bidders.

At the same time, competition policy needs to consider the potential for higher social value resulting from concentrated ownership of spectrum: incumbents may be able to leverage existing infrastructure to provide services more efficiently, and some aggregation of spectrum may be necessary to develop a new generation of services (for example, a high-speed wireless data service). This is a difficult trade-off.

Another goal in many auction settings is raising revenues. A pro-efficiency argument for maximizing revenues is that substituting auction revenues for revenues raised through distortionary taxes saves the deadweight loss of those taxes. Yet maximizing revenues often conflicts with the goal of creating a com- 
petitive market for wireless services. First, reducing the amount of available spectrum would typically increase auction revenue, but it restricts the development of wireless services. Second, selling the rights to be a monopolist can raise much more revenue than selling licenses to many competing providers, to the detriment of postauction competition and efficiency.

Our view is that, in practice, the regulators should primarily focus on allocating spectrum efficiently and creating postauction competition in the wireless services market, and they should worry less about revenues. The reason for our view is that wireless communication services typically have large and persistent positive spillovers to the entire economy as well as substantial consumer welfare benefits resulting from both static and dynamic competition (Rosston 2003). Moreover, the demand for wireless services is strong and growing, and the amount of available and usable spectrum is limited. In practice, it means that even without restricting the spectrum or boosting revenues by increasing postauction market power, spectrum auctions lead to high revenues as long as either new entrants are attracted to participate in the auction or incumbents can be enticed to compete for larger quantities of spectrum. Finally, as our examples show, in some cases there may be no trade-off between raising revenue and efficient allocation of spectrum.

Low revenues in the auction are bad if they are the result of a flawed auction design, tacit collusion, or successful entry deterrence by the incumbents. These cases should be a reason for concern. If, at some point in time, the amount of available spectrum becomes large relative to demand, then revenue considerations may become more important. Moreover, the regulator may impose minimum prices for spectrum to assure that the spectrum is used for commercial wireless services only if there are no better alternative uses of the spectrum. Looking at the recent wireless spectrum auctions, we seem to be far away from that point. Therefore, in the rest of the paper, we focus on promoting efficient allocation of spectrum and competition in the wireless services market and not raising auction revenues.

\section{Policy Instruments to Enhance Competition}

Regulators have a variety of options to enhance competition. We discuss six: set-asides, bidding credits, spectrum caps, band plan, auction design, and antitrust enforcement. Typically, each policy option affects competition both in the auction and in the downstream market for wireless services. We focus on how the policy choices affect the overall market efficiency, and hence we consider the effects of competition in the auction mostly in terms of how it will affect postmarket conduct via creating or blocking new entry and/or allowing or disallowing efficient aggregation of spectrum. 


\subsection{Set-Asides}

The regulator reserves one or more blocks of spectrum for a particular type of bidder. The most common use is to set aside a block of spectrum for new entrants and exclude incumbents (appropriately defined) from bidding on the set-aside block. This approach is highly effective in motivating participation by new entrants, since it guarantees that a new entrant will win at least the setaside block. But it may result in entry by firms with higher costs and less attractive offerings than incumbents. The approach has been used in auctions in many countries, such as the United States, the United Kingdom, and Canada.

\subsection{Spectrum Caps}

Spectrum caps limit the quantity of spectrum that can be held by an operator in a particular geographic area. Spectrum caps are applied either within the current auction or to a category of spectrum beyond the current auction. For example, in most of the European $3 \mathrm{G}$ auctions, bidders could win at most one block. In the United States, before the personal communications service (PCS) auctions in 1994, the Federal Communications Commission (FCC) set a cap for commercial mobile radio spectrum, including both cellular and PCS bands. The spectrum cap approach enables entrants to bid for a greater quantity of newly available spectrum than incumbents. Both spectrum caps and set-asides limit the excessive concentration of spectrum, but their drawback is that they may prohibit efficient aggregation of spectrum.

\subsection{Bidding Credits}

Bidders of a favored type get a percentage discount on any winning bids. For example, new entrants may get a 25 percent bidding credit. In this case, a new entrant submitting a bid of $\$ 100$ would have to pay only $(1-.25) \times \$ 100=$ $\$ 75$ if the bid were to win. Bidding credits typically apply to all blocks on which the favored bidders bid. ${ }^{1}$

\subsection{Band Plan}

The band plan determines how the spectrum is sliced into blocks and partitioned into geographic areas. The band plan impacts competition and the range of services that can be offered. If the service areas are too large, small local operators may be excluded; if the service areas are too small, auction complexity and aggregation/exposure risk make it difficult for a bidder to succeed in aggregating enough licenses for a more expansive business plan. If the licenses are too small in frequency and cannot be easily aggregated, then some broadband services may become infeasible. Coordinating band plans across countries also promotes entry by international providers. It enables more compatible services

\footnotetext{
${ }^{1}$ Bidding credits to encourage new entry are rarely used. The most common use of bidding credits has been in U.S. spectrum auctions, where they are granted to small businesses. See our discussion in Sections 4.4 and 5.3.
} 
and leverages economies of scale in both service provision and hardware manufacturing.

\subsection{Auction Design}

Features of the auction design, such as the bid format, the reserve price, and the information policy (for example, anonymous versus transparent bidding), also can influence auction competition. For example, allowing package bids may help bidders aggregate spectrum efficiently. Some auction designs may favor incumbents and help them deter efficient entry. Finally, some designs are more prone to tacit collusion among bidders, which may reduce efficiency if firms refrain from bidding to keep prices low and, hence, prices are not used to select the most efficient providers.

\subsection{Antitrust Enforcement}

Antitrust enforcement plays an important role in encouraging competition before, during, and after the auction. Before and during the auction, strict rules again bidder collusion are needed to discourage anticompetitive behavior, so that prices in the auction can guide an efficient allocation. After the auction, antitrust oversight and enforcement can prevent anticompetitive mergers and other firm behavior that undermines competition in the market for wireless services.

\section{Models of Competition in Spectrum Auctions}

As we discussed in the Introduction, in a simple environment an ascending auction allocates the spectrum to the firm that values it the most. Such allocation is good for overall efficiency only if firm valuations are aligned with social values. Yet there are many practical situations in which such a simplistic rule is not optimal. We now discuss some of these practical considerations.

\subsection{Firms Are Willing to Pay More for a Monopoly Position}

Consider spectrum for a new service in which two identical licenses are available for auction. A firm can bid for either one or two licenses. Bidding for both licenses has the advantage that the firm, if it wins, secures a monopoly in the new service. Assuming (realistically) that the monopoly profits are more than twice the duopoly profits, one firm is apt to win both licenses. Social welfare, however, may be higher with two firms or with one firm. On one hand, the monopolist is likely to exercise market power after auction (which is inefficient); on the other hand, there may be important cost savings from not having two independent service providers. It is important to note that the inefficiency of a monopolistic provider is often not only due to the static underprovision of service 
(which could be potentially fixed by rate regulation) but also due to lower competitive pressure to innovate, build out coverage, and develop new services. ${ }^{2}$

If a regulator decides that it is better to avoid creating a monopoly, then all that is required is a spectrum cap limiting each bidder to a maximum quantity of spectrum. Such a solution is common in practice. For example, the U.S. FCC limited licensees in the satellite radio (digital audio radio service) auction to one of the two licenses available, but they subsequently allowed the two licensees to merge.

\subsection{Model 1: The Effect of a Set-Aside for New Entrants}

Most spectrum auctions involve incumbents. The new spectrum can go to incumbents or new entrants or both. The asymmetry between incumbents and entrants tilts the auction result toward sustaining the status quo market structure. To illustrate the issues, in the rest of this section we discuss a few simple models of competition in auctions with incumbents and entrants. The models are based on those of Jehiel and Moldovanu (2003).

Suppose first that there is one additional license for sale via an ascending auction. Before the auction, there is one incumbent in the industry who already owns $M$ licenses. Suppose that if there are $k$ firms after the auction, then the profit per license will be $\pi(k)$. Thus, $\pi(1)$ is the monopoly profit per license and $\pi(2)$ is the duopoly profit per license. We assume throughout that $\pi(k)$ is a decreasing function of $k$. We also assume that for small $k$ social welfare is increasing in $k$, and that for large $k$ it is potentially decreasing. These assumptions can be made endogenous using one of the standard models of industry competition, with some economies of scale making the total surplus nonmonotonic in $k$. Essentially, competition transfers existing profits from firms to consumers (via lower markups) and yields efficiency gains from expanded consumption, but it potentially increases costs as additional firms incur fixed costs to provide service.

Assume that all the firms are symmetric, other than the distinction between the new entrants and the incumbent. We assume that there are many potential entrants. Compare the following two scenarios: In scenario A, the incumbent and entrants bid on equal terms. In scenario $\mathrm{B}$, the incumbent is not allowed to bid for the new license; it is set aside for new entrants.

Jehiel and Moldovanu (2003) illustrate the results of such an auction. In scenario $\mathrm{A}$, the incumbent would win the new license at price $p_{\mathrm{A}}=\pi(2)$, and there would remain only the single monopoly firm in the industry. In scenario $\mathrm{B}$, the license would go to one of the new entrants also at a price of $\pi(2) .^{3}$

To see the first claim, notice that a new entrant would bid for the license up

\footnotetext{
${ }^{2}$ We admit that from the theoretical point of view, the effect of competition on innovation is ambiguous. Yet casual observations of the telecommunication services industry suggest that competition speeds up innovation.

${ }^{3}$ In all models, the auction format is an ascending clock auction.
} 
to $\pi(2)$, the entrant's postauction profit. If the incumbent does not win the license, then postauction incumbent's total profit is $M \pi(2)$, or $\pi(2)$ per license. Alternatively, if the incumbent wins the new license, then its total profits, gross of the price of that license, are $(M+1) \pi(1)$. Therefore, the incumbent is willing to pay up to the difference of gross profits between winning and losing:

$$
V=(M+1) \pi(1)-M \pi(2)=\pi(2)+[M+1][\pi(1)-\pi(2)] .
$$

The last expression on the right-hand side is the incumbent's monopoly rent per license, $[\pi(1)-\pi(2)]$ on all $M+1$ licenses if it succeeds in deterring entry. The incumbent is willing to bid that much more to protect its existing market power.

In the second scenario, the potential entrants would bid the price up to $\pi(2)$. This would result in the same auction revenues as in the first scenario and a more competitive postauction market structure.

We admit that this model, as well as the models presented below, is stylized and does not do justice to the full complexity of spectrum auctions, where firms are asymmetric (beyond the asymmetry between entrants and incumbents), have private information about their business plans and cost structures, and have a value of additional licenses that is not necessarily linear in terms of the number of licenses because of complementarities among different blocks or because of decreasing marginal values of additional licenses. This simple model is intended to highlight only the incumbent bias in auctions that can lead to an inefficient allocation of the licenses as a result of an inefficient postauction market structure. Furthermore, it highlights that revenues in unrestricted auctions do not need to be strictly higher than those in auctions with spectrum caps or set-asides.

One extension of the model is to allow multiple incumbents. Suppose one license is up for auction and there are $k$ incumbents. Competition between the incumbents would drive prices up to $\pi(k)$, and entry would not occur since the entrants would be willing to bid only up to $\pi(k+1)$. Whether it is efficient to set aside the spectrum would depend on what is more important: having another provider or allowing incumbents to aggregate more spectrum and leverage economies of scale. ${ }^{4}$

\subsection{Model 2: Small Auction Participation Costs and Asymmetric Profits}

Now, in addition to the setup of model 1, suppose that there is a small cost $c$ to participate in the auction and that firms differ in their profits per licensethat is,

$$
\pi_{i}(k) \neq \pi_{j}(k)
$$

\footnotetext{
${ }^{4}$ If instead $k$ additional licenses are available and there is a limit of one license per bidder, then the incumbents can split the market, and the bidding stops at $\pi(k+1)$ instead of $\pi(k)$, resulting in no entry and low revenues. This is what happened in the German 1999 spectrum auction. For a model with such a split as the unique equilibrium outcome, see Grimm, Riedel, and Wolfstetter (2003). Such a split can be especially inefficient if the incumbents differ in their ability to use the spectrum efficiently or if it is more efficient to aggregate the spectrum rather than split it.
} 
where $i$ and $j$ represent different firms. It is realistic to assume that these differences are large compared to $c$ but small compared to the effect of the market structure: $\pi_{i}(k)>\pi_{j}(k+1)$ for all $i$ and $j$. The differences between $\pi_{i}(k) \neq$ $\pi_{j}(k)$ are assumed to be private information before the auction. In addition, the auctioneer sets a small minimum reserve price $P_{\mathrm{MIN}}$ such that $P_{\mathrm{MIN}}<\pi_{i}(2)$ for every bidder $i$.

Again consider two scenarios: In scenario A, the incumbent and entrants bid on equal terms. In scenario $B$, the new license is set aside for new entrants. This game is more difficult to analyze because of the participation decision. To simplify, suppose that there are two potential entrants other than the incumbent and that $c$ is small enough that if faced only with competition from another entrant, each entrant is willing to pay the participation cost $c^{5}$

What is the equilibrium outcome now? Subsequent to the participation decisions of the firms, the game is as in model 1. But now, in scenario A, the entrants realize that competition is futile and that hence they are strictly better off not participating in the auction, resulting in very low revenue. In scenario $\mathrm{B}$, the entrants enter and auction revenue is equal to the minimum of their $\pi_{i}(2)$.

There are two effects for efficiency. First, using the set-aside changes the postauction market structure from a monopoly to duopoly. Second, if one of the new entrants is more efficient than the incumbent, not using the set-aside can lead to a less efficient firm using the new license. This can happen even if the ranking of social efficiency is aligned with the ranking of profits because (1) as we discussed in the previous model, the incumbent has additional reasons to bid aggressively to protect profits from existing licenses, and (2) in our scenario, we assumed that this motive is stronger than any differences in efficiency. Of course, the opposite outcome is also possible: if the incumbent is the more efficient firm and the set-aside is used, the license would be inefficiently allocated to the entrant.

\subsection{Model 3: Bidding Credits for New Entrants}

Suppose that there is a single incumbent with one license, one additional license is up for auction, there are many potential entrants, and all firms other than the incumbent are symmetric. The auctioneer offers bidding credits of $x$ percent for all new entrants, so that if the winning price is $p$, then a new entrant would pay only $(1-x) p$. Then a potential entrant is willing to bid up to

$$
p=\pi(2) /(1-x)>\pi(2)
$$

Bidding credits have two possible impacts on the auction outcome, depending on whether the term $2 \pi(1)-[1+1 /(1-x)] \pi(2)$ is positive or negative.

If the term is positive, then the incumbent will still win the auction because it is willing to bid up to $p=2 \pi(1)-\pi(2)$, while an entrant is willing to bid

\footnotetext{
${ }^{5}$ For a similar model, see Milgrom (2004, sec. 6.3.1).
} 
only up to $\pi(2) /(1-x)$. The price will be $\pi(2) /(1-x)$, and the market will remain concentrated. In that case, even though the bidding credits do not affect the market allocation, they do increase revenue from the auction.

If the term is negative, then a new entrant will win the auction and pay a price net of the bidding credit that is $\pi(2)$, so the revenues are not affected. ${ }^{6}$ In addition, the market becomes more competitive. As before, if there are costs of participating in the auction, then auction revenues could increase in both cases. Also, as before, if the firms are heterogeneous, bidding credits may reduce efficiency (and revenues) if they make an entrant win the auction when the incumbent is more efficient.

Combining the two cases of model 3 , we summarize as follows. If the regulator is interested in finding a balance between maximizing revenues and promoting competition, then bidding credits of moderate size are a win-win situation: they increase revenues without worsening the market structure. ${ }^{7}$ As usual, there are many caveats to this analysis. We discuss one, which is a major concern in practice.

The regulator should be worried that a new entrant would use the bidding credit to obtain the license and then resell it, either directly or indirectly via a 100 percent wholesale contract, to the incumbent. Suppose that the incumbent can create an affiliate, or front, that would follow such a strategy, and suppose that $x$ is small enough that without such a strategy the incumbent would win the auction at a price $\pi(2) /(1-x)$. Instead, it could drop out of the auction and let the front win at the same price but recapture the bidding credit. In this way the incumbent would still end up with the license and pay only $\pi(2)$. Such a strategy can undo any benefits of increased competition. Moreover, creating an opportunity for such rent seeking induces private parties to make socially wasteful expenditures to benefit from the credits. In addition, the regulator must expend resources to determine which parties qualify for the credits. Similar issues arise in the case of set-asides or spectrum caps: firms interested in getting around these restrictions may try to use third parties to meet the requirements legally but then use contracts to violate the intent of the requirements in an economic sense. One possible solution is to use tests similar to the ones used by antitrust agencies in determining market shares to outlaw any contracts that would undo any bidding credits, set-asides, or spectrum caps intended to increase postauction competition. This is not always easy to implement, however, since the regulator may not have as strong a mandate to intervene in contracting as does the competition authority and since such monitoring of firms is complicated.

In practice, improving welfare using either bidding credits or set-asides is

${ }^{6}$ If there is only one entrant, then the price net of the bidding credit would be $[2 \pi(1)-$ $\pi(2)](1-x)>\pi(1)(1-x)$. In that case, revenues go down. To see this, note that the revenues are decreasing in $x$ in this case, and at $x$ such that the incumbent and entrant are willing to bid up to exactly the same price, the revenues are $\pi(2)$, which is the same as without bidding credits.

${ }^{7}$ Milgrom $(2004$, p. 237) shows another model in which moderate bidding credits improve revenues in the auction. 
complicated. For example, when using bidding credits, a commonly advocated solution is to estimate the additional social value of a new entrant in dollars and then give that lump-sum bidding credit to all new entrants. However, such estimates are difficult to obtain. Moreover, it is possible that the additional social value depends on the type of the entrant and also on which of the current incumbents would be the alternative. In that case, a simple credit of a lump sum for all new entrants would not be efficient, and it may not even be possible to achieve the efficient allocation with a simple auction with bidder-specific bidding credits. In addition, should the regulator ever post a number representing the value of an extra entrant, one can expect it to be a source of controversy and lobbying by the interested parties. This may explain why in practice we more often see the regulators imposing spectrum caps or using set-asides rather than using bidding credits.

Spectrum caps, set-asides, and bidding credits can be generalized and combined into a variety of quantity-based and/or price-based instruments. This is most readily done in auctions that optimize across all bids to maximize an objective subject to constraints. Spectrum caps and set-asides are examples of constraints on the bids, but these and other constraints can also be imposed on the outcome. For example, as a constraint on spectrum concentration, one could require that the sum of the squared spectrum shares not exceed a particular level.

\section{Discussion of Policy Instruments in Practice}

\subsection{Small Business and New Entrant Distinctions}

Before discussing the different competition policy tools, it is important to distinguish the social tools used in the United States to promote other goals. The United States mixes competition and social policy by creating in the auctions a special group of bidders known as designated entities. The FCC's auction authority stemmed from the Omnibus Budget and Reconciliation Act of 1993 (OBRA 1993; Pub. L. No. 103-66; 107 Stat. 312 [1993]). Section 309 of OBRA 1993 provides the FCC's auction authority but also includes several directions for the implementation of auction authority. First, it directs that maximization of revenues shall not be the goal of the auction. In addition, section 309(j) provides that the FCC should ensure the opportunity of small businesses, businesses owned by women and minorities, and rural telephone companies (collectively known as designated entities) to participate in the auction process and in the provision of service. Because of the Supreme Court's decision in Adarand Constructors, Inc. v. Pena (515 U.S. 200 [1995]), implementation of the provisions of $309(\mathrm{j})$ evolved to provide specific incentives to promote small businesses only. In most cases, small businesses have also been new entrants, but not all new entrants to wireless service are small businesses. For example, MCI considered bidding in the first PCS auctions. Although MCI was a large telecommunications 
provider at the time, it was not a wireless operator and would have been a new entrant into wireless service.

In the major spectrum auctions, the FCC faced a trade-off in trying to comply with the law that true small businesses have a reasonable chance at winning licenses and also have the financial ability to compete in the wireless marketplace. Allowing larger companies to back a small business in a variety of ways and help to provide a source of funding for postauction competition addresses the latter objective while potentially conflicting with the spirit of the small business provisions.

The FCC's initial rules permitted larger telecommunications companies to back certain smaller companies, such as Alaska Native Wireless and Salmon PCS. Some people viewed such companies as fronts for the larger companies. As a result, the FCC tightened the control requirements over time, and fewer small businesses participated in the subsequent auctions. Ultimately, the economic key to small business policies is whether they lead to successful competition in the market for wireless services. These effects are evaluated by ignoring the difficulties with the definition and enforcement of small businesses and by instead looking at the impact on entry and competition. In our opinion, the use of bidding credits for small businesses in the U.S. spectrum actions did not have a major impact on postauction competition.

\subsection{Set-Asides and Spectrum Caps}

Although set-asides and spectrum caps are not identical, they often serve a similar purpose when the spectrum cap is sufficiently binding on all incumbents: they provide a guarantee that a new entrant will be able to acquire spectrum. One difference is that with set-asides, there typically are specific licenses allocated for new entrants, while with spectrum caps, the auction determines the allocation subject to constraints on the quantity of spectrum for which any single bidder can bid. In addition, set-asides often are a simple way of implementing a spectrum cap that is supposed to apply to the incumbents as a sum rather than individually. For example, if there are $40 \mathrm{MHz}$ of spectrum for sale, with two incumbents, if the regulator wants to guarantee that a new entrant wins at least $10 \mathrm{MHz}$, the rules can either set aside that $10 \mathrm{MHz}$ or impose a spectrum cap of $15 \mathrm{MHz}$ on each of the incumbents. The second solution has the side effect of imposing a restriction on how the incumbents can split their winnings. A third alternative would be to impose a cap of $30 \mathrm{MHz}$ on the sum of winnings by the incumbents, but that can complicate the rules of the auction more than the set-aside.

The FCC has used both spectrum caps and set-asides. For the broadband PCS $\mathrm{A}$ and B blocks, incumbent cellular carriers were prevented from buying inregion licenses because of a $45-\mathrm{MHz}$ spectrum cap. The $25 \mathrm{MHz}$ of cellular spectrum combined with the $30-\mathrm{MHz}$ PCS blocks would have caused them to exceed the cap. However, they could buy the PCS A and B licenses in adjacent markets to expand their geographic footprints. The FCC set aside the broadband 
PCS C block for small businesses. The definition of small business precluded most of the incumbent wireless providers from participating in the auction. To qualify, the business had to have less than $\$ 125$ million in annual revenue and less than $\$ 500$ million in assets.

In addition to limiting participation in the broadband C-block auction to small businesses, the FCC offered the bidders installment payments: 10 percent down and the rest paid over 10 years. Unfortunately, the top three bidders in the auction declared bankruptcy, and the fourth largest bidder failed to make its down payment. Their bids comprised approximately 75 percent of the $\$ 10$ billion in C-block net bids.

In 2003, the Supreme Court ruled in favor of NextWave, the largest bidder to declare bankruptcy, with bids of $\$ 4.2$ billion in the C-block auction (Federal Communications Commission v. NextWave Personal Communications, Inc., 537 U.S. 293 [2003]). The Court ruled that while the firm was reorganizing under bankruptcy protection, the FCC did not have the right to take back its licenses for failure to make payments. The FCC had to return to NextWave the licenses that it had cancelled and subsequently reauctioned. In 2004, as part of settlement with the FCC, NextWave agreed to return 75 percent of its licenses. In 2005, those returned licenses were auctioned by the FCC. Finally, in March 2005, the FCC approved NextWave's \$3 billion sale to Verizon of the licenses it did not return to the FCC as part of the settlement. The set-aside and installment payments were intended to promote the "participation in the provision of spectrumbased services" by small businesses (FCC, Second Memorandum Opinion and Order in PP Docket No. 93-253, FCC 94-215, 9 FCC Rcd. 7245, 59 Fed. Reg. 44272, par. 3 [August 26, 1994]). But that objective was hardly achieved, and the public was deprived of the benefits of most of the $30 \mathrm{MHz}$ of spectrum in the $\mathrm{C}$ block for almost 10 years.

In the European $3 \mathrm{G}$ auctions, regulators used variants of set-asides and spectrum caps. ${ }^{8}$ In the United Kingdom, the government auctioned five $3 \mathrm{G}$ licenses with four incumbent $2 \mathrm{G}$ providers. Each provider was limited to purchasing at most a single $3 \mathrm{G}$ license. The fifth license was set aside for a new entrant. In the Netherlands, although there was a limit of a single license per participant, there were five existing $2 \mathrm{G}$ providers, so new entrants did not have the same guarantee of a new entrant license. Having the same number of licenses as incumbents limited competition in the auction; however, the end result was that the Netherlands had five providers at the end of the auction, the same number of competitors as the United Kingdom. Switzerland had four incumbents and four licenses, and again prices were extremely low, since the potential new entrants aligned with the incumbents before the bidding began.

Germany imposed a similar spectrum cap, ensuring that at least four firms won licenses. In the end, prices in the German auction were high, and six firms ended up with licenses. Austria used a design similar to that of the Germans

\footnotetext{
${ }^{8}$ Much of the European discussion is based on Klemperer (2004).
} 
and also had six licensees, but it did not have high revenue. In both countries, only four operators ultimately survived.

A lesson from the European $3 \mathrm{G}$ auctions is that spectrum caps and set-asides can have a major impact on auction outcomes, but other factors, such as timing and rules against collusion, also play an important role. In addition, the extent of ex post competition can be influenced by the regulator with these instruments, but the underlying economies of scale may well undo the regulator's desire for more competitors.

In the recent Canadian advanced wireless services (AWS) auction, the government used a band plan similar to the U.S. AWS band plan but set aside three blocks for new entrants. The definition of new entrant focused on entry to the nationwide business and ruled out the three largest wireless providers in Canada: Telus, Rogers, and Bell Canada. All others, including existing small regional carriers, were eligible to bid on both the set-aside and non-set-aside blocks in any area of the country. This created competition between the three incumbents in the auction because there were only two large blocks and one small block available in any geographic area for them. The set-aside resulted in at least one new entrant in every area of the country, but the amount of new entry varied by region.

Set-asides and spectrum caps have been used to ensure that new entrants have a chance to provide service and additional competition in the market for wireless service. However, there is a potential sacrifice from set-asides and spectrum caps - the incumbent wireless providers may be the most efficient providers of service. If the sacrifice of efficiency is not outweighed by the additional competition engendered by a new, less efficient competitor, then there is a real cost to using set-asides and spectrum caps. For example, an incumbent provider may be able either to integrate additional spectrum into an existing network to provide additional capacity at low cost or to combine with existing spectrum to provide a new service that requires more capacity than would be possible without the additional spectrum. If the new entrant would not increase competition by innovating or lowering prices but would incur build-out costs and additional operating costs, promoting new entry would not be socially efficient.

Set-asides and spectrum caps should be used when there is a real chance that the additional competition will increase consumer choice and lead to efficient competition. This needs to be determined before using these tools.

\subsection{Bidding Credits}

Bidding credits differ from set-asides or binding spectrum caps in that they do not guarantee a new entrant (or small business) winner. In the United States, bidding credits have historically been used for small businesses, but theoretically they could be used for all new entrants. A bidding credit can serve at least two different purposes. Ayres and Cramton (1996) and model 3 described above show that under certain circumstances, the increased competition in the auction 
due to a bidding credit can increase revenues at the same time that it increases the possibility of a new entrant. A second feature of a bidding credit is that it allows the government to put a value (in either absolute or percentage terms) on having a new entrant. With a set-aside, the government must decide in advance of the auction, without knowing the cost of having a new entrant, whether it wants to set aside a license for a new entrant.

With a bidding credit, the government could decide that it is willing to sacrifice $\$ 1$ billion in revenues to get a new entrant. In this case, an incumbent would be forced to bid at least $\$ 1$ billion more than a new entrant to get the license. Similarly, the government could decide that the benefits of a new entrant are worth 25 percent of the license price, and it would be willing to sacrifice that much revenue (although the Ayres and Cramton [1996] analysis shows that this would be an upper bound on the revenue loss).

The maximum cost of a bidding credit is the face value of the credit. For example, a 25 percent bidding credit may be bid away completely if the two most efficient providers of service each qualify for the credit. Instead of bidding $\$ 100$ for a license without a credit, they would bid up to $\$ 133.33$, or $\$ 100 /(1-.25)$. The net revenue to the government would not change in this circumstance. In FCC auctions, for example, there is evidence that much, if not all, of the bidding credit has been bid away as qualified entities compete for the license. For example, in the FCC's regional narrowband PCS auction, small business bidding credits of 25 percent were available on one of two $50 / 50-\mathrm{kHz}$ paired licenses and one of three $50 / 12.5-\mathrm{KHz}$ paired licenses. The net prices for the licenses with bidding credits ended up being slightly higher than the net prices for licenses without bidding credits.

A variant on the bidding credit was the FCC's use of a reserve price to trigger the $700-\mathrm{MHz}$ C-block open-access provisions, which mandated a minimum amount for the licenses but did not reveal the differential between the value of the licenses with and without the open-access provisions. The FCC wanted to impose open-access conditions on the $\mathrm{C}$ block but not if the revenue received would be perceived to be too low. As a result, it put a reserve price of $\$ 4.64$ billion in auction 73 on the $C$ block with the requirement that if the reserve price were met, the licensee would be required to comply with the open-access provisions (and if the reserve were not met, the block would be reauctioned without these provisions). The reserve price can be seen as meeting a political challenge because the FCC did not allow bids for the license without the openaccess provision (akin to allowing bids with and without a bidding credit). This is a variant of a bidding credit because it differentially provides advantages to a provider willing to comply with open-access provisions. ${ }^{9}$

\footnotetext{
${ }^{9}$ See Brusco, Lopomo, and Marx (2011) for an analysis of how bidding credits can outperform such a contingent reauction design.
} 


\subsection{Spectrum Availability and Band Plan}

Perhaps the most important issue in spectrum auctions and wireless competition is the amount of spectrum available to the market (Hazlett and Munoz 2009). To provide wireless communication, providers need a combination of spectrum, technology, and capital (such as cell sites and back haul). With less spectrum, providing the same amount of service generally requires more advanced technology and more investment in capital, such as more cell sites. While auctions tend to garner headlines because of the billions of dollars raised, a successful spectrum policy would result in low prices for spectrum because the supply would be large enough that the scarcity value would be reduced. Such a policy conflicts with the frequent government objective of increasing short-term government revenues.

In the U.S. broadband PCS auctions, the initial band plan had two big blocks of spectrum and four smaller nonadjacent blocks of spectrum. In early 1994, the FCC reformulated the band plan and was able instead to have three large blocks of spectrum and three smaller blocks all in adjacent frequencies. This change to the band plan increased the effective number of viable license winners and also made the licenses more substitutable, thereby increasing competition in the auction and in the aftermarket for wireless service.

\subsection{Auction Format}

Much has been written about different ways to auction spectrum. The focus of this paper is designing auctions to maximize the chance that licenses are assigned efficiently. With the substantial uncertainty regarding the efficient assignment and valuations by different bidders, there are different auction formats that can be used to achieve efficiency. However, there also are auction formats that some governments have adopted that are unlikely to achieve an efficient allocation of licenses. For example, the initial spectrum auctions in New Zealand, as discussed in Milgrom (2004) and McMillan (1994), were not well designed, and the experience from these auctions helped the FCC avoid similar inefficiency and negative public perceptions (Kwerel and Rosston 2000).

In 1994, the FCC adopted the novel simultaneous multiple-round (SMR) auction. In an SMR auction, all licenses are up for bid at the same time and the auction does not close until bidding ends on all licenses. In some versions of the rules, bidders choose bid prices, while in others the auctioneer runs a price clock for each license and bidders select the licenses or packages of licenses on which they wish to bid (with the prices going up for licenses with excess demand). The SMR design facilitates pursuing efficient backup strategies among substitutable licenses and aggregation of complementary licenses. The auction process is aided by activity rules that require the bidders to bid on a minimum amount of spectrum ${ }^{10}$ each round to maintain their eligibility to bid in future

\footnotetext{
${ }^{10}$ For the purpose of auction eligibility rules, the FCC measures the spectrum associated with license as the product of bandwidth and population (that is, MHz-pops).
} 
rounds. Before the auction begins, bidders put up money to acquire an initial maximum eligibility level. If the bidder does not meet the required activity, its maximum eligibility is reduced. Over the course of the auction, the required activity level increases. These measures are intended to ensure that bidders do not hold back on bidding until very late in the auction. For more specific details of the auction design, see McMillan (1994).

Although this auction format had many benefits and worked well (Ausubel et al. 1997; McMillan 1994; Milgrom 2004), there were a few problems with the format. Some of the problems, such as potential tacit collusion and fat-finger bidding (inadvertently entering the wrong bid amount), were easily solved with minor changes to the auction systems (Kwerel and Rosston 2000). Others, such as the exposure problem, required more changes to the auction format and rules. A bidder might suffer from potential exposure if its business plan requires the aggregation of multiple licenses. For example, if it is successful in acquiring only a portion of the required licenses, it might end up losing money by paying too high a price for the final pieces of its package, by stopping bidding and being stuck with an insufficient set of licenses, or by paying a bid withdrawal penalty to drop the incomplete package of licenses. Fear of this outcome could cause the bidder to reduce its initial bids or even not bid at all. To address the exposure problem, the FCC has used limited combinatorial or package bidding in two auctions. In the first - auction 51 for regional narrowband PCS — there was only a single round of bidding and there were no nonpackage bids, so the system was not tested in a rigorous manner.

In its recent 700-MHz auction (auction 73), the FCC used package bidding on the $\mathrm{C}$ block. The auction provided for package bidding on three predefined packages of licenses in the C block: (1) the 50 States package containing the eight Regional Economic Area Grouping (REAG) licenses comprising the continental United States, Alaska, and Hawaii, (2) the Atlantic package containing the two REAG licenses comprising Puerto Rico, the U.S. Virgin Islands, and the Gulf of Mexico, and (3) the Pacific package containing the two REAG licenses comprising the U.S. Pacific territories. As it turned out, there were few package bids during the auction. Ultimately, only a single package was won: the Pacific package. Google was the only party bidding on the 50 States package, and it stopped bidding when the open-access reserve price was reached. For Google, as a new entrant with no existing spectrum holdings and seeking nationwide coverage and to trigger the C-block open-access provisions, the availability of a nationwide package may have been important to its participation in the auction.

Bazelon (2009) argues that the C block was not the best choice for implementing package bidding because the license size for the $\mathrm{C}$ block was relatively large. Instead, the exposure risk was probably greater on other blocks available in the auction that had smaller geographic license areas. In addition, the use of a package bid for one block when there are other substitute blocks created substantial strategic issues in the auction. Brusco, Lopomo, and Marx (2009) and Bazelon (2009) discuss how Verizon was able to use the eligibility rules 
strategically to pay a much lower price for the $\mathrm{C}$ block than if there had been a more efficient auction design. With a more efficient design, it is possible that auction participants other than Verizon would have acquired more licensesthat is, they were willing to pay more for C-block licenses than Verizon paid. Yet since the auction eligibility rules prevented them from moving from the other blocks to the $\mathrm{C}$ block, they were unable to compete for the C-block spectrum. As a result, the C-block licenses sold for substantially less than comparable aggregations of spectrum in the other blocks. ${ }^{11}$

Many other countries have adopted auction formats similar to the FCC's standard SMR auction. For example, Canada has used the SMR format. One significant difference between large countries (for example, United States, Canada, and India) and smaller countries is that large countries typically are divided into many small license areas, whereas many other countries award nationwide licenses. Auctioning nationwide licenses can help reduce the geographic exposure problem and make running the auction more straightforward, but it makes it more difficult for a business with a plan to serve a small area to acquire spectrum.

Sweden adopted a novel format for its 2008 auction. It allowed bidders to withdraw bids from specific licenses without a bid withdrawal penalty, so long as they bid on another license. This withdrawal rule may make sense when all of the licenses in an auction are substitutes, as were most of the licenses in the Swedish auction. In that way, if the price of a specific license is out of line with substitutes, then bidders can bid on the substitute licenses. Ultimately, there should not be much difference in the license prices. However, when some of the licenses are not good substitutes, the lack of a withdrawal penalty can create strategic incentives. In the Swedish auctions, 12 of the licenses were very similar (they were all paired spectrum), two others were similar to the 12 but had guard band considerations, and one license was not similar. This dissimilar license was unpaired spectrum suitable for time division duplex (TDD) technology, whereas the others were paired spectrum suitable for frequency division duplex (FDD) technology. As a result, a bidder could bid on the 14 FDD licenses and not reveal its true demand for a TDD license until the end of the auction, without pushing up the price of the TDD license. If bidders have budget constraints and competitors want both a paired and an unpaired license, bidding on the paired licenses to drive up the price of the paired licenses before competing for the unpaired license (or vice versa) could be a reasonable strategy. But that might result in an inefficient allocation of licenses.

In the Canadian AWS auction in 2008, most of the auction was for AWS spectrum. However, in each geographic area, the government also included licenses for PCS and 1670-MHz spectrum. These licenses generally were not substitutable for the AWS licenses (nor were they complementary in the sense that they could not really be combined to provide a wider band service). As a result, at times bidders used them to park eligibility during the auction, because they

\footnotetext{
${ }^{11}$ The $\mathrm{C}$ block also had open-access provisions that may account for some of the price difference.
} 
were a relatively cheap place to maintain eligibility points. This ultimately caused the prices for those licenses to be higher than they would have been, and it possibly caused some to go unsold (for example, if a bidder was interested in buying a large number of those licenses to cover a large geographical area, he could be discouraged from doing so if he saw that some of the licenses got expensive for strategic reasons not related to the value of these licenses).

Beginning in 2008, the United Kingdom adopted the package clock auction for its spectrum auctions (Ausubel et al. 2006; Cramton 2009). This auction allows package bids but retains the simple price discovery of the SMR auction by starting with an initial clock stage where bidders express their demand for licenses as the auctioneer raises prices. The Netherlands, Denmark, and Austria also adopted the package clock auction design. A key innovation of the design is that it allows a technology-neutral auction, where the auction configures the spectrum band plan for either (or both) devices or technologies that require paired spectrum blocks (long-term evolution [LTE]) or those that do not (worldwide interoperability for microwave access [WiMAX]). Allowing different technologies to compete in the auction requires a package auction in which bidders bid on packages of lots. The design includes an innovative pricing rule and activity rule, both of which tend to reduce strategic bidding and improve price discovery. As with all package auctions, this design may favor bidders bidding on larger packages.

In general, the lessons from spectrum auctions are that it is beneficial to include in the same auction either substitutable licenses or nearly substitutable licenses and to auction complementary licenses in a way that makes it easier for bidders to resolve the exposure problem. Including nonrelated licenses (neither substitutes nor complements) in the same auction does not tend to increase efficiency and may create strategic incentives during the auction that ultimately end up reducing the efficiency of allocation of licenses.

\subsection{Antitrust Enforcement and Regulation}

Antitrust enforcement is a key feature of competition policy. However, it generally is not a useful tool to prevent the creation of excessive spectrum concentration in auctions. To run an efficient auction, bids must be sincere. If after the close of an auction, a bidder could not acquire a license because of antitrust enforcement, that could impair the efficiency of the auction process. For example, if an incumbent was able to rescind its bid because of antitrust enforcement, it would have an incentive to hold up the auction process by winning and expecting either to be granted a license or to be denied a license and not be forced to pay its bid. In the second circumstance, it would be able to delay competition and/or raise the costs of its rivals. If the firm were required to pay its bid and then to spin off its new holding (or to pay a bid withdrawal penalty and have the government reauction the license), it still might find it worthwhile to delay competition while it challenged the antitrust authorities. 
There are at least three important roles for antitrust: in ex ante auction rules, as discussed above with regard to spectrum caps; in the auctions, to prevent collusion among bidders; and in the marketplace, for wireless services.

Ex ante auction rules generally come from the regulatory agency rather than from the antitrust authority. However, there are times where the antitrust authority works with the regulator to ensure a competitive auction, which is an appropriate and effective role. Preventing collusion between bidders during an auction is extremely important to efficiency and revenue and to the overall integrity of the spectrum auction process. Antitrust authorities may face difficult decisions about allowing or preventing preauction agreements between potential competitors.

Most antitrust scrutiny will come after the conclusion of the license assignment process (whether by auction or some other method). For example, there have been a large number of wireless mergers. Generally, the mergers are of two types: geographic extension mergers and within-area consolidation mergers. Usually the geographic extension mergers cause no competitive concern because they replace one provider with another and do not remove any competitors. Consolidation mergers usually generate more antitrust scrutiny. There can be efficiency justification for such mergers: the additional spectrum controlled by a single company can increase its technological flexibility. At the same time, there can also be an excessive concentration of market power with regard to spectrum or wireless services that causes a concern. Usually such concerns can be solved with targeted divestitures.

There is also a role for the regulation of the interconnection of wireless services to promote efficient competition. Competitors need to work together to provide network service, and as such they may not agree on efficient levels of intercarrier compensation. For example, few people would have adopted wireless service in the United States had they not been able to connect to traditional wire-line telephones. Initially, many of the wire-line companies and their state regulators viewed wireless as a service for the rich, and they used it to provide income for the traditional landline companies. Calls from wireless phones to landline phones were typically charged 3 cents per minute for termination on the landline network. However, calls to wireless callers did not receive symmetric treatment; in fact, the wireless provider often had to pay the landline provider the same 3 cents per minute even though the call was going the other direction and even though the wireless provider was incurring the cost of terminating the call. The FCC's implementation of the 1996 Telecommunications Act interpreted reciprocal termination as symmetric termination rates. This simple regulatory intervention nearly immediately reduced termination rates overall to less than a penny a minute and even less over time. As a result, wireless companies offer plans with free nights and weekends that would have been cost prohibitive without the change in termination rates.

Ensuring that bidders in auctions know that they will have the ability to interconnect with incumbent providers at reasonable and symmetric rates makes 
it more likely that a new entrant can build a viable business and thus more likely that a potential new entrant would attempt to enter. This, in turn, will increase competition in the auction for licenses.

\section{Conclusion}

Well-designed spectrum auctions can play an important role in fostering a competitive wireless industry. Of even greater importance is the quantity of spectrum made available for wireless services. Spectrum is an essential input. The more spectrum allocated to wireless services, the more competition can be sustained. Other regulatory policies, including rules for interconnection, number portability, tower sharing, and roaming, also affect the competitiveness of the market for wireless services.

Spectrum auctions provide a fast and effective means of assigning spectrum to wireless operators. We believe that the primary objective of these auctions should be efficiency-putting the spectrum in the hands of those best able to use it-not raising revenue. Efficient auctions raise substantial revenues, and focusing more on revenues likely distorts the outcome away from social welfare maximization.

We have discussed a number of instruments that can be used by the regulator to enhance competition, both in the auction and in the market for wireless services. These include spectrum caps, bidding credits, and set asides. Experience with these instruments has been mixed. In some cases they worked well in promoting social welfare, such as the initial spectrum cap in the U.S. broadband market. In other cases, such as the programs to benefit small businesses in the U.S. C-block PCS auction, the result was lengthy delay in the use of the spectrum because of subsequent bankruptcy and litigation. Our conclusion is that these instruments must be used with care. The phrase attributed to the Hippocratic Oath very much applies: first, do no harm.

\section{References}

Ausubel, Lawrence, Peter Cramton, R. Preston McAfee, and John McMillan. 1997. Synergies in Wireless Telephony: Evidence from the Broadband PCS Auctions. Journal of Economics and Management Strategy 6:497-527.

Ausubel, Lawrence, Peter Cramton, and Paul Milgrom. 2006. The Clock-Proxy Auction: A Practical Combinatorial Auction Design. Pp. 115-38 in Combinatorial Auctions, edited by Peter Cramton, Yoav Shoham, and Richard Steinberg. Cambridge, Mass.: MIT Press.

$\rightarrow$ Ayres, Ian, and Peter Cramton. 1996. Deficit Reduction through Diversity: How Affirmative Action at the FCC Increased Auction Competition. Stanford Law Review 48: 761-815.

$\rightarrow$ Bazelon, Coleman. 2009. Too Many Goals: Problems with the $700 \mathrm{MHz}$ Auction. Information, Economics, and Policy 21:115-27.

$\rightarrow$ Borenstein, Severin. 1988. On the Efficiency of Competitive Markets for Operating Licenses. Quarterly Journal of Economics 103:357-85. 
$\rightarrow$ Brusco, Sandro, Giuseppe Lopomo, and Leslie Marx. 2009. The "Google Effect" in the FCC's $700 \mathrm{MHz}$ Auction. Information, Economics, and Policy 21:101-14.

$\rightarrow$. 2011. The Economics of Contingent Re-auctions. American Economic Journal: Microeconomics 3:165-93.

$\rightarrow$ Coase, R. H. 1959. The Federal Communications Commission. Journal of Law and Economics 2:1-40.

Cramton, Peter. 2009. Spectrum Auction Design. Working paper. University of Maryland, Department of Economics, College Park.

$\rightarrow$ Grimm, Veronika, Frank Riedel, and Elmar Wolfstetter. 2003. Low Price Equilibrium in Multi-unit Auctions: The GSM Spectrum Auction in Germany. International Journal of Industrial Organization 21:1557-69.

$\rightarrow$ Hazlett, Thomas, and Roberto Munoz. 2009. A Welfare Analysis of Spectrum Allocation Policies. RAND Journal of Economics 40:424-54.

$\rightarrow$ Jehiel, Phillippe, and Benny Moldovanu. 2003. An Economic Perspective on Auctions. Economic Policy 36:269-308.

Klemperer, Paul. 2004. Auctions: Theory and Practice. Princeton, N.J.: Princeton University Press.

$\rightarrow$ Kwerel, Evan, and Gregory Rosston. 2000. An Insiders' View of FCC Spectrum Auctions. Journal of Regulatory Economics 17:3:253-89.

$\rightarrow$ McMillan, John. 1994. Selling Spectrum Rights. Journal of Economic Perspectives 8:14562.

Milgrom, Paul. 2004. Putting Auction Theory to Work. Cambridge: Cambridge University Press.

$\rightarrow$ Rosston, Gregory. 2003. The Long and Winding Road: The FCC Paves the Path with Good Intentions. Telecommunications Policy 27:501-15. 